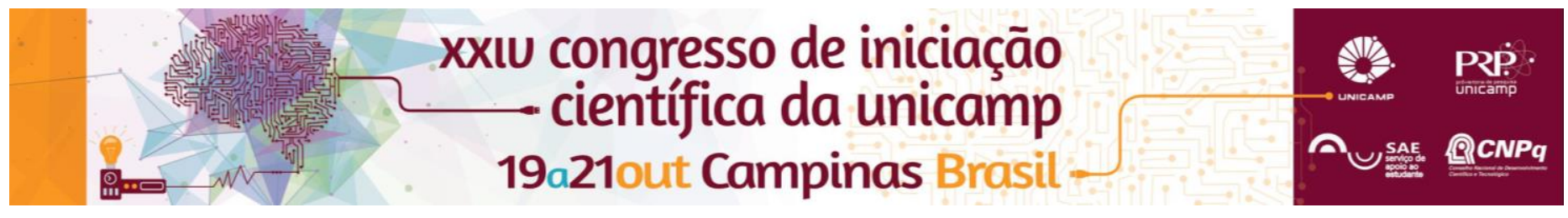

\title{
Avaliação do Autocuidado de Gestantes Hipertensas: um estudo piloto
}

\author{
Andiara Bianchi Bruscagin Pin*, Antonieta Keiko Kakuda Shimo
}

\begin{abstract}
Resumo
A hipertensão arterial é uma das doenças mais comum a aflingir mulheres duante a gestação e é, no Brasil, a causa de morte materna mais frequente. São cinco as formas de hipertenção que podem ocorrer durante a gestação, que se diferem quanto a prevalência, fravidade e efeitos sobre o feto. Objetiva-se avaliar o autocuidado das gestantes hipertensas participantes do grupo de pré-natal de alto risco do Hospital Estadual Sumaré Dr. Leandro Franceschini HES, utilizando a Escala para Avaliar a Capacidade do Autocuidado - EACAC.
\end{abstract}

\section{Palavras-chave:}

Hipertensão arterial, Autocuidado, Pré-Natal Alto Risco

\section{Introdução}

A hipertensão arterial ocorre em 10 a 22\% das gestações $^{1}$, e, no Brasil, é a causa de morte materna mais frequente ${ }^{2}$, constituindo um dos principais problemas de saúde pública ${ }^{3}$.

As formas de hipertensão que podem ocorrer e complicar a gestação são: 1) pré-eclâmpsia ou doença hipertensiva específica da gravidez (DHEG); 2) elcâmpsia; 3) hipertensão crônica; 4) pré-eclâmpsia sobreposta a hipertensão crônica ou nefropatia; 5) hipertensão gestacional ${ }^{1}$. Elas diferem quanto a prevalência, a gravidade e os efeitos sobre o feto ${ }^{1}$.

Durante a gravidez, diversas mudanças ocorrem com a mulher ${ }^{4}$, gerando déficits de autocuidado 4 , que devem ser compensados e supridos pelo enfermeiro, com 0 intuito de preservar o bem-estar da gestante e do feto ${ }^{4}$.

Para Dorothea Orem, teorista de enfermagem, o autocuidado é a capacidade que o indivíduo tem de cuidar de $\mathrm{si}^{5}$. As capacidades de desenvolver as ações para o autocuidado são aprendidas e estão sujeitas a alguns fatores condicionantes ${ }^{5}$. Cerca de $67,7 \%$ das mulheres hipertensas não seguem corretamente 0 tratamento medicamentoso ${ }^{6}$, demonstrando um autocuidado prejudicado.

$O$ instrumento utilizado para a coleta de dados foi a Escala para Avaliar a Capacidade do Autocuidado EACAC, que contém 24 itens com cinco possíveis respostas do tipo Likert.

Trata-se de um estudo piloto, que teve como objetivo avaliar o autocuidado das gestantes hipertensas participantes do grupo de pré-natal de alto risco do Hospital Estadual Sumaré - HES.

\section{Resultados e Discussão}

O questionário com dados sócio econômicos e obstétricos e a EACAC foram aplicados em 6 gestantes hipertensas participantes do grupo de pré-netal de alto risco do HES.

Foram entrevistas mulheres entre 26 e 39 anos, com uma média de 32 anos de idade. Houve uma igualdade entre a declaração de raça (branca, parda e preta). $67 \%$ das gestantes completaram o ensino médio, e a mesma proporção possui trabalho remunerado. A totalidade era casada e residentes da cidade de Sumaré, Monte Mor, Hortolândia e Nova Odessa. Quatro gestantes (67\%) estavam no $2^{\circ}$ trimestre da gestação, e duas estavam no terceiro trimestre. $33 \%$ descobriram a hipertensão no primeiro trimestre da gestação, enquanto $67 \%$ já possuíam uma hipertensão de base, também presente em gestações anteriores. A totalidade era multípara, com uma média de 3,3 gestações, 2,3 partos e 2,1 filhos vivos e $20 \%$ apresentou diabetes mellitus em alguma gestação anterior. No total, foram quatorze partos em que 57\% (8) foram por cirurgia cesárea e $27 \%$ por via vaginal com episiotomia.

$\mathrm{Na}$ escala de auto cuidado, 50\% apresentou escore correspondente ao autocuidado muito bom (entre 89 e 104 pontos), 17\% bom (entre 89 a 104 pontos) e $33 \%$ ótimo (entre 105 e 120 pontos). Os itens com menores escores foram os itens "Sempre que posso, faço ginástica e descanso no meu dia a dia", "No meu dia-adia, geralmente encontro tempo para cuidar de mim mesmo" e "Sempre acho tempo para mim mesmo". Em média, o escore foi de 96,1 pontos, correspondente a um autocuidado bom.

\section{Conclusões}

$67 \%$ das gestantes apresentavam já apresentavam hipertensão crônica, ou seja, diagnosticada antes da gestação ${ }^{1}$. A cirurgia cesárea foi a escolha na maioria dos partos anteriores. $O$ autocuidado das gestantes hipertensas pode ser classificado como bom.

\section{Agradecimentos}

Agradeço à minha querida Orientadora Antonieta, por todo carinho e ensinamento. Agradeço à minha família, por todo o apoio e ajuda.

1 Oliveira CA, Lins CP, Sá RAM, Netto HC, Bornia RG, Silva NR, Junior JA Síndromes hipertensivas da gestação e repercussões perinatais. Rev Bras Saúde Matern. Infant. 2006; 6(1):93-98

2 Oliveira SMJV, Persinotto MOA. Revisão de literatura em enfermagem sobre hipertensão arterial na gravidez. Rev Esc Enferm USP. 2001; 35(3):214-22

3 Chaim SRP, Oliveira SMJV, Kimura AF. Hipertensão arterial na gestação e condições neonatais ao nascimento. Acta Paul Enferm. 2008; 21(1):53-8

4 Sampaio TAF, Santana TD, Hanzelmann RS, Santos LFM, Montenegro HRA, Martins JSA, Helena AAS, Ferreira DC. Cuidados de Enfermagem prestados a mulheres com HipertensãoGestacional e Pré-eclâmpsia. Revista Saúde Física \& Mental - UNIABEU. 2013; 2(1):36-45

5 Sa SP, Santos DM, Robers LMV, Andrade MS, Coimbra CAQ, Cruzó TJP. Uma proposta para a

mensuração do autocuidado em idosos. Cogitare Enferm. 2011; (16)4:661-6

6 Moura SLO, Silveira GM, Feitoza MS, Albuquerque MES, Morais RS, Aguiar DT. Adesão ao tratamento farmacológico da hipertensão arterial sistêmica: análise de um grupo de hipertensos. Ver enferm UFPE. 2015; 9(2):683-91 